\title{
Weekend and evening planned colonoscopy activity: a safe and effective way to meet demands
}

\section{두)(1) $\odot$}

\section{Authors}

Shimaa A. Afify ${ }^{1}$, Omnia M. Abo-Elazm², Ishak I. Bahbah ${ }^{3}$, Mo H. Thoufeeq ${ }^{1}$

Institutions

1 Endoscopy unit, Sheffield Teaching Hospitals, University of Sheffield, Sheffield, UK

2 National Cancer Institute, Department of Biostatistics and Cancer Epidemiology, Cairo University, Cairo, Egypt

3 Faculty of Medicine, Al-Azhar University, Damietta, Egypt

submitted 29.5.2020

accepted after revision 8.3.2021

\section{Bibliography}

Endosc Int Open 2021; 09: E1026-E1031

DOI 10.1055/a-1477-2963

ISSN 2364-3722

(C) 2021. The Author(s).

This is an open access article published by Thieme under the terms of the Creative Commons Attribution-NonDerivative-NonCommercial License, permitting copying and reproduction so long as the original work is given appropriate credit. Contents may not be used for commercial purposes, or adapted, remixed, transformed or built upon. (https://creativecommons.org/licenses/by-nc-nd/4.0/)

Georg Thieme Verlag KG, Rüdigerstraße 14,

70469 Stuttgart, Germany

Corresponding author

Shimaa A. Afify, Endoscopy unit, Sheffield Teaching Hospitals, Sheffield, UK

drshima202@yahoo.com

\section{ABSTRACT}

Background and study aims Colonoscopy is the "gold standard" investigation for assessment of the large bowel that detects and prevents colorectal cancer, as well as nonneoplastic conditions. The Joint Advisory Group (JAG) on Gastrointestinal Endoscopy recommends monitoring key performance indicators such as cecal intubation rate (CIR) and adenoma detection rate (ADR). We aimed to investigate the quality of colonoscopies carried out during evening and Saturday lists in our unit and compare them against JAG standards of quality for colonoscopies.

Patients and methods We retrospectively collected and analyzed demographical and procedure-related data for non-screening colonoscopies performed between January 2016 and November 2018. Evenings and Saturdays were defined as the out-of-hour $(\mathrm{OOH})$ period. We compared the outcomes of the procedures done in these against the working hours of the weekdays. We also wanted to explore whether the outcomes were different among certain endoscopists. Other factors that could affect the KPIs, such as endoscopist experience and bowel preparation, were also analyzed.

Results There were a total of 17634 colonoscopies carried out; $56.9 \%$ of the patients $(n=10041)<70$ years old. Key Performance Indicators (KPIs) of weekday, evening, and Saturday colonoscopies regarding the CIR and ADR met the JAG standards as they were above $93 \%$ and $24 \%$, respectively. Advanced colonoscopists had better KPIs when compared to the non-advanced colonoscopists, with CIR at $97.6 \%$ vs. $93.2 \%$ and $A D R$ at $40.8 \%$ vs. $26 \%$, respectively.

Conclusions JAG standards were maintained during colonoscopies done on weekdays, evenings, and Saturdays. Advanced colonoscopists had higher CIR and ADRs.

\section{Introduction}

Colonoscopy, the "gold standard" investigation for assessing the large bowel, detects and prevents colorectal cancer and allows diagnosis, biopsy, and therapy to be undertaken [1] and is important for both diagnosis and treatment of non-neoplastic conditions [2-4]. In isolated cases, colonoscopy may lead to rare but serious complications [5-7] and suboptimal colonoscopy may be associated with increased rates of interval cancers $[8,9]$. As with many technical skills, there may be a variation in quality of practice among clinicians [10-12]. The most commonly used quality indicator for colonoscopy is adenoma detection rate (ADR) of endoscopists. ADR can be affected by a number of variables, such as quality of bowel preparation, cecal intubation rate (CIR) [9-11], and colonoscopy withdrawal time (CWT) [13-16].

In 2013, the Joint Advisory Group on Gastrointestinal Endoscopy (JAG), the British Society of Gastroenterology (BSG), and the Association of Colo-proctology of Great Britain and Ireland commissioned a new working group to review existing and de- 
fine quality assurance measures and key performance indicators (KPIs) for colonoscopy [17]. With the increased demand that endoscopy services are under and the "just about coping" situation, many services are not meeting national waiting time targets. Twenty percent of Acute National Health Service (NHS) units in England, $64 \%$ of units in Northern Ireland, $40 \%$ units in Scotland, and $42 \%$ in Wales were unable to meet urgent suspected cancer targets in 2017 [18].

The national survey of endoscopy done in 2017 [18] showed that endoscopy services are under pressure with many patients not meeting waiting time targets and found that there is a potential to increase endoscopy service to a 7-day working pattern to meet the increased demand. However, evidence suggested that staffing would be a significant issue. JAG recommendations include a minimal unadjusted cecal intubation at $90 \%$, and colonoscopists should aspire to achieve $95 \%$ unadjusted cecal intubation [16]. ADR is recommended to be $15 \%$ or more with an aspirational ADR of $20 \%$. The polyp detection rate can be used as a marker of ADR $[16,19]$

In the 2017 JAG census, shortages of endoscopists and nursing staff were found to be the biggest barrier that impeded units in meeting the demand [18]. Services introduced extended working hours during the week and on weekends to increase capacity; $66 \%$ of acute NHS units perform endoscopy most or every weekend. Several NHS hospitals were offering "insourcing" in their unit as well as "outsourcing" patients to other services; both are used by approximately $25 \%$ of acute English units [18]. The 2019 JAG UK survey trend suggested that $17.2 \%$ of services outsourced activity to external providers and $36.1 \%$ of services reported that they insourced activity [20]. Our hospital provides endoscopy service on weekday evenings and all day on Saturday with the service offered by our own staff. This study aimed to assess whether the quality indicators were maintained during the weekends and on Saturdays. We hypothesized that the quality indicators were likely to be maintained during these times, allowing us to add extra endoscopy activities to meet the increasing demands for colonoscopy.

\section{Patients and methods}

\section{Study Design}

We retrospectively collected data from 17634 patients who underwent non-screening colonoscopies in Sheffield Teaching Hospitals, United Kingdom, from January 2016 to November 2018. Ethical approval was obtained from the hospital's endoscopy user group. The majority of our colonoscopies done outof-hours $(\mathrm{OOH})$ were non-screening. Taking this into consideration and the fact that screening colonoscopies have high polyp detection, we excluded bowel cancer screening colonoscopies to avoid the risk of selection bias.

\section{Data collection and outcomes}

The quality indicators for colonoscopy defined by the JAG include cecal intubation rate (CIR) and ADR. We also calculated the mean polyps per procedure (MPPP) for each group. ADR is a validated quality measure for a colonoscopy; it was calculated as the proportion of procedures in which at least one adenoma was detected for an endoscopist over the total number of colonoscopies. MPPP and mean numbers of adenomas per procedure were defined as the total number of polyps or adenomas detected divided by the total number of colonoscopies performed, respectively. Evenings (5:30 pm to $9 \mathrm{pm}$ ) and Saturdays were defined as $\mathrm{OOH}$ periods. We compared the outcomes of the procedures done in these against the working hours of the weekdays. We also wanted to explore whether outcomes were different among endoscopists. Therefore, we classified endoscopists as advanced and non-advanced colonoscopists. Advanced colonoscopists were defined as BCSP (Bowel cancer screening program)-accredited colonoscopists or those that were performing advanced SMSA (size, morphology, site, access) level 3, 4 colonic polypectomies regularly [21].

\section{Statistical analysis}

Data were analyzed using SPSS version 25 (SPSS Inc., Chicago, Illinois, United States). Numerical data were expressed as mean and standard deviation or median and range as appropriate. Qualitative data were expressed as frequency and percentage. Chi-square test (Fisher's exact test) was used to examine the relation between qualitative variables. For quantitative data, a comparison between two groups was done using either a student's t-test or Mann-Whitney test (non-parametric t-test) as appropriate. A Kruskal-Wallis test used for comparing more than two groups. $P \leq 0.05$ was considered significant. Logistic regression was done to give an adjusted odds ratio and measure the magnitude of the effect of different factors on ADR and CIR; factors entered into models were: timing of the procedure, working team, and adequacy of bowel preparation.

\section{Results}

During the study period, 17634 colonoscopies were performed: $20.4 \%$ in patients $>70$ years old and $56.9 \%$ in patients $<70$ years old. The ages of 3992 patients $(22.6 \%)$ were unavailable ( Table 1). There was a significant difference in the distribution of age group with the working times, as Saturdays and evenings had a lower distribution of patients $>70$ years compared to weekdays. Overall, CIR was $>90 \%$ and ADR was over $15 \%$ during all three sessions.

CIR was significantly higher in patients $<70$ years old $(93.8 \%)$ compared to the $\geq 70$ years old group $(90.3 \%)$. ADR was higher in the $\geq 70$ years old group at $36 \%$ vs. $24.6 \%$ in the $<70$ years old group. The MPPP was significantly higher in the $\geq 70$ years old group (0.70) compared to the $<70$ years old group $(0.45), P<$ 0.001. ( $\triangleright$ Table 2 )

The most common indication for colonoscopy in the study group was a change in bowel habits ( $\mathbf{F i g}$. 1). ADR was higher in patients undergoing colonoscopy for polyp surveillance and patients presenting with abnormal radiological investigations. CIR was higher in patients scoped for polyp surveillance and IBD-related indications ( $\triangleright$ Table $\mathbf{3}$ ).

The adequacy of bowel preparation was analyzed based on procedure time, i.e., weekdays, evenings, and Saturdays. We categorized the quality of bowel preparation into excellent, 
$\checkmark$ Table 1 Age of patients

\begin{tabular}{|l|l|l|}
\hline Age of patients & & $\mathbf{N}(\%)$ \\
\hline \multirow{2}{*}{ Valid } & $\geq 70$ & $3601(20.4 \%)$ \\
\hline & $<70$ & $10041(56.9 \%)$ \\
\hline & Total & $13642(77.4 \%)$ \\
\hline Unavailable data & & $3992(22.6 \%)$ \\
\hline Total & & $17634(100 \%)$ \\
\hline
\end{tabular}

adequate, and inadequate. Overall, the quality of bowel preparation was better during the evenings ( $\triangleright$ Table 4 ).

There was no significant overall difference in the CIR for procedures done during weekdays, Saturdays, or evenings. ADR was higher for procedures done on weekdays (28.8\%) when compared to those done in the evenings (24.4\%) and Saturdays (24.2\%). Although both groups met JAG standards, advanced colonoscopists had statistically significant higher KPIs with CIR of $97.6 \%$ and ADR of $40.8 \%$ when compared to the non-advanced colonoscopists, who had CIR of $93.2 \%$ and ADR of $26 \%$ ( $\triangleright$ Table 5 and $>$ Fig. 2 ).
ADR was higher in patients that had adequate preparation (29.4\%) when compared to those with preparation that was excellent $(24.6 \%)$ or inadequate $(28.9 \%)$. CIR was statistically significantly higher in patients with adequate or excellent (94.9\%, 95.1\%) compared to those with inadequate preparation (90.1\%). MPPP was significantly higher in the advanced colonoscopist group and for procedures done during weekdays and procedures with adequate bowel preparation ( $>$ Table 5 ).

Multiple logistic regression models for factors affecting ADR demonstrated that colonoscopies that were done on Saturdays and evenings were less likely to detect polyps when compared to weekdays, adjusted for other factors in the model and confounders $(\mathrm{OR}=0.92,95 \% \mathrm{Cl}: 0.81-1.04, P=0.175)$. This is likely due to the larger number of patients on weekdays in comparison to Saturdays and evenings. Patients with inadequate preparation were less likely to have adenomas detected in comparison to those with adequate preparation adjusted for other factors in the model and confounders. (OR $=0.94,95 \% \mathrm{Cl}$ : $0.85-$ 1.04, $P=0.281)$. Advanced colonoscopists were significantly more likely to detect adenomas in their procedures after controlling for other factors in the model $\mathrm{OR}=1.86$, $95 \% \mathrm{Cl}$ : $1.65-$ 2.11, $P<0.001$ ( $>$ Table 6).

- Table 2 Age at procedure and different study variables

\begin{tabular}{|c|c|c|c|c|}
\hline \multirow{2}{*}{\multicolumn{2}{|c|}{ Variables }} & 70 or over & Under 70 & \multirow[t]{2}{*}{$P$ value } \\
\hline & & N (\%) & N (\%) & \\
\hline \multirow[t]{3}{*}{ Working time } & Weekdays & $3204(89 \%)$ & $7576(75.5 \%)$ & \multirow[t]{3}{*}{$<0.001$} \\
\hline & Saturdays & $245(6.8 \%)$ & $1224(12.2 \%)$ & \\
\hline & Evenings & $152(4.2 \%)$ & $1241(12.4 \%)$ & \\
\hline CIR & Yes & $3252(90.3 \%)$ & $9417(93.8 \%)$ & $<0.001$ \\
\hline ADR & Yes & $1295(36 \%)$ & $2473(24.6 \%)$ & $<0.001$ \\
\hline MPPP mean(SD) & & $0.70(1.22)$ & $0.45(0.99)$ & $<0.001$ \\
\hline
\end{tabular}

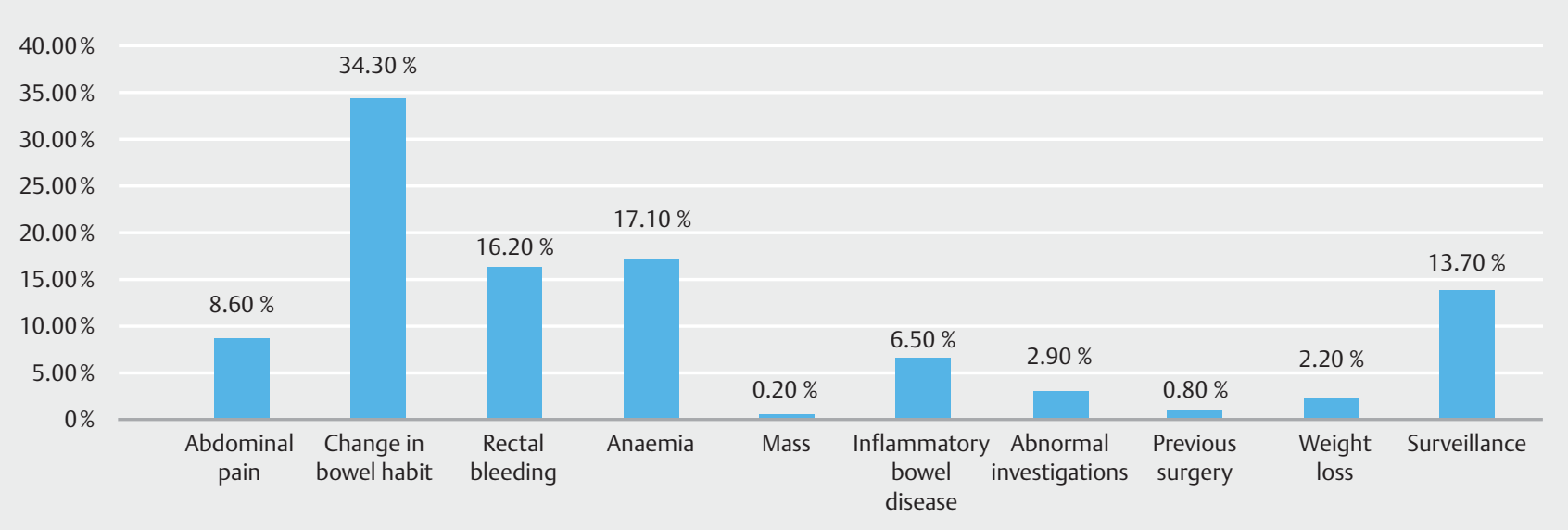

- Fig. 1 Indications for colonoscopy. 
- Table 3 Indication for colonoscopy with ADR and CIR

\begin{tabular}{|c|c|c|c|c|}
\hline Indication & ADR\% & $P$ value & CIR\% & $P$ value \\
\hline Abdominal pain & $18.7 \%$ & $<0.001$ & $93.1 \%$ & 0.27 \\
\hline Anemia & $26.2 \%$ & $<0.001$ & $91.7 \%$ & $<0.001$ \\
\hline Inflammatory bowel disease & $12.0 \%$ & 0.03 & $96.0 \%$ & $<0.001$ \\
\hline Polyp surveillance & $41.1 \%$ & $<0.001$ & $96.4 \%$ & 0.001 \\
\hline Abnormal radiological investigations & $31.2 \%$ & $<0.001$ & $87.7 \%$ & $<0.001$ \\
\hline Weight loss & $26.2 \%$ & 0.08 & $90.5 \%$ & 0.001 \\
\hline
\end{tabular}

- Table 4 Adequacy of bowel preparation in relation to working hours

\begin{tabular}{|l|l|l|l|}
\hline Adequacy of bowel preparations & Weekdays & Saturdays & Evenings \\
\hline & $\mathbf{N}(\%)$ & $\mathbf{N}(\%)$ & $\mathbf{N}(\%)$ \\
\hline Adequate & $7043(51.6 \%)$ & $1055(52.6 \%)$ & $688(53.8 \%)$ \\
\hline Excellent & $3600(26.4 \%)$ & $500(24.9 \%)$ & $395(30.9 \%)$ \\
\hline Inadequate & $3013(22.1 \%)$ & $450(22.4 \%)$ & $196(15.3 \%)$ \\
\hline$P \leq 0.05$ is statistically significant. & & & \\
\hline
\end{tabular}

Table 5 ADR and CIR with different variables

\begin{tabular}{|c|c|c|c|c|c|c|c|}
\hline \multicolumn{2}{|l|}{ Variables } & CIR & $P$ value & ADR & $P$ value & MPPP & $P$ value \\
\hline \multirow[t]{3}{*}{ Timing } & Weekday & $12696(93.6 \%)$ & \multirow[t]{3}{*}{0.068} & 3906 (28.8\%) & \multirow[t]{3}{*}{0.009} & 0.49 (0.99)a & \multirow[t]{3}{*}{0.009} \\
\hline & Saturday & 1962 (94.9\%) & & $500(24.2 \%)$ & & $0.38(0.84) b$ & \\
\hline & Evening & $1876(93.6 \%)$ & & $490(24.4 \%)$ & & $0.39(0.85) b$ & \\
\hline \multirow[t]{2}{*}{ Team } & Advanced & $2090(97.6 \%)$ & \multirow[t]{2}{*}{0.009} & $875(40.8 \%)$ & \multirow[t]{2}{*}{0.009} & $0.65(1.06)$ & \multirow[t]{2}{*}{0.009} \\
\hline & Non-advance & $14444(93.2 \%)$ & & $4021(26 \%)$ & & $0.44(0.94)$ & \\
\hline \multirow[t]{3}{*}{ Quality } & Adequate & 8320 (94.9\%) & \multirow[t]{3}{*}{0.009} & $2579(29.4 \%)$ & \multirow[t]{3}{*}{0.009} & $0.49(0.98) b$ & \multirow[t]{3}{*}{0.009} \\
\hline & Excellent & 4279 (95.1\%) & & $1107(24.6 \%)$ & & $0.40(0.89) a$ & \\
\hline & Inadequate & $3280(90.1 \%)$ & & $1050(28.9 \%)$ & & $0.49(1) b$ & \\
\hline
\end{tabular}

CIR, cecal intubation rate; ADR, adenoma detection rate; MPP, mean polyp per procedure.

Variables sharing same letters are not statistically different from each other, while those with different letters are significantly different after Bonforoni correction.

In a multiple logistic regression model for factors affecting CIR, colonoscopies that were done on Saturdays had more likelihood for $\mathrm{CIR}$ in comparison to weekdays $(\mathrm{OR}=1.14,95 \% \mathrm{Cl}$ : $0.91-1.43, P=0.256)$, while those done in evening shifts were associated with lower CIR, adjusted for other factors in the model. Colonoscopies with excellent preparation had the highest likelihood of high CIRs; however, we could not identify a significant association between excellent preparation and CIR in the adjusted model. Advanced colonoscopists were more likely to have higher CIR than non-advanced colonoscopists after controlling for other model factors ( $\triangleright$ Table 7 ). After adjusting these findings to age, we found that advanced teams were more likely to achieve high CIRs (OR=2.53; $95 \% \mathrm{Cl}: 1.84-3.48, P<$ 0.001).

\section{Discussion}

There is evidence to suggest that when quality is overseen, outcomes are improved in colonoscopy [22,23]. Quality indicators of colonoscopy such as CIR and ADR need to be met to give patients the maximum benefit of the service provided, so our study aimed to explore the KPIs at various sessions. Our study found that JAG standards were maintained for colonoscopies done on weekdays, evenings, and Saturdays.

A cost-benefit analysis was not performed as this was not in the study's remit, but we found that by utilizing evenings and Saturdays, an additional 2005 and 2067 colonoscopies were done at thos respective times.

With NHS and other service providers aspiring to deliver a seven-day service for all our patients, these additional activities 


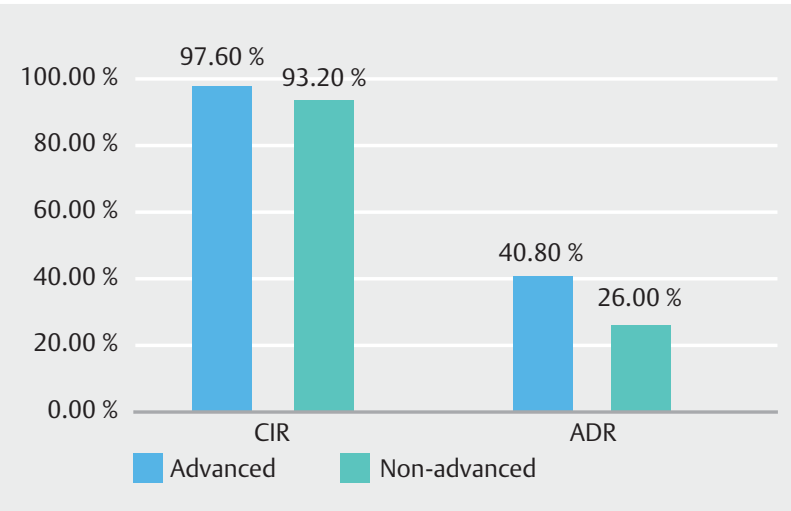

Fig. $2 \mathrm{KPIs}$ of advanced versus non-advanced colonoscopists.

could hugely complement these aspirations. In a large study survey of more than 750,000 responders relating to primary care services, the majority of responders who mentioned that they had issues accessing services mentioned that having healthcare provision on Saturdays would be helpful for them [23]. Some patients may find evenings and Saturdays more suitable. This was anecdotally noticed during the study period, but we did not collect data on it. All patients were given a choice, based on the availability of slots and urgency based on indications.

The $\mathrm{OOH}$ sessions were also utilized for other emergency and planned endoscopies, such as upper gastrointestinal endoscopies, flexible sigmoidoscopies, BCSP colonoscopies, bowel scopes, and endoscopic retrograde cholangiopancreatography. As the purpose of our study was to look at non-BCSP colonoscopies only, we did not include these in this study.

Although JAG standards were maintained overall, advanced colonoscopists had higher CIR, ADR, and MPPP. These factors should be considered when job plans and operational plans are made for utilization of capacity.

We also noted that the quality of bowel preparation was better in the evenings. Previous studies have shown variations in the quality of bowel cleansing between sessions [24], including evening sessions [25]. As noted by Subaramanian et al [25], this could be related to patients having evening scopes being given same-day preparation instructions as opposed to split dosing or the day before. Further studies may be required to look at cleansing quality in evenings specifically.

The ADR and CIR showed comparable results on Saturdays and evenings to regular weekdays, and KPIs were preserved. We also note that at the time of submission of this manuscript,

- Table 6 Multivariate analysis of factors affecting ADR

\begin{tabular}{|c|c|c|c|c|}
\hline Factors affecting ADR & Unadjusted OR, $95 \% \mathrm{CI}$ & $P$ value for unadjusted $O R$ & Adjusted OR, $95 \% \mathrm{Cl}$ & $P$ value for adjusted $O R$ \\
\hline Weekday & \multicolumn{4}{|l|}{ (Reference) } \\
\hline Saturday & $0.82(0.73-0.93)$ & 0.002 & $0.92(0.81-1.04)$ & 0.175 \\
\hline Evening & $0.81(0.71-0.92)$ & 0.002 & $0.97(0.85-1.10)$ & 0.610 \\
\hline Adequate & \multicolumn{4}{|l|}{ (Reference) } \\
\hline Excellent & $0.83(0.76-0.91)$ & $<0.001$ & $0.87(0.79-0.95)$ & 0.003 \\
\hline Inadequate & $0.96(0.86-1.06)$ & 0.445 & $0.94(0.85-1.04)$ & 0.281 \\
\hline Advanced Team & $1.88(1.67-2.11)$ & $<0.001$ & $1.86(1.65-2.11)$ & $<0.001$ \\
\hline
\end{tabular}

Table 7 Multivariate analysis of factors affecting CIR

\begin{tabular}{|c|c|c|c|c|}
\hline Factors affecting CIR & Unadjusted OR, $95 \% \mathrm{Cl}$ & $P$ value for unadjusted $O R$ & Adjusted OR, $95 \% \mathrm{Cl}$ & $P$ value for adjusted $O R$ \\
\hline Weekday & \multicolumn{4}{|l|}{ (Reference) } \\
\hline Saturday & $1.20(0.96-1.51)$ & 0.107 & $1.14(0.91-1.43)$ & 0.256 \\
\hline Evening & $0.93(0.76-1.15)$ & 0.522 & $0.86(0.69-1.06)$ & 0.147 \\
\hline Adequate & \multicolumn{4}{|l|}{ (Reference) } \\
\hline Excellent & $1.09(0.90-1.30)$ & 0.361 & $1.06(0.89-1.27)$ & 0.521 \\
\hline Inadequate & $0.41(0.35-0.48)$ & $<0.001$ & $0.42(0.36-0.49)$ & $<0.001$ \\
\hline Advanced Team & $2.48(1.80-3.40)$ & $<0.001$ & $2.53(1.84-3.48)$ & $<0.001$ \\
\hline
\end{tabular}


units across the world were likely to face huge challenges to meet the huge backlog demands following restrictions secondary to COVID-19 [26, 27]. Units should consider performing colonoscopies on weekends and evenings as an alternative route to meet targets.

We note that other studies had been done on the quality of $\mathrm{OOH}$ service in specialties such as orthopedic trauma [28]. However, to the best of our knowledge, this is the first study looking at planned endoscopy activity done $\mathrm{OOH}$. There has only been a conference poster presentation looking at $\mathrm{OOH}$ colonoscopies that were presented from our unit in 2017 [29].

\section{Conclusions}

In conclusion, the JAG quality standards for colonoscopy were maintained during colonoscopies done in the evening and on Saturdays, the same as on weekdays, which may allow for extra list slots to face the service demand. Similarly, we found that advanced colonoscopists had higher CIR and ADRs than nonadvanced colonoscopists.

\section{Competing interests}

The authors declare that they have no conflict of interest.

\section{References}

[1] Rex DK, Cutler CS, Lemmel GT et al. Colonoscopic miss rates of adenomas determined by back-to-back colonoscopies. Gastroenterology 1997; 112: 24-28

[2] Bowles C], Leicester R, Romaya C et al. A prospective study of colonoscopy practice in the UK today: are we adequately prepared for national colorectal cancer screening tomorrow? Gut 2004; 53: 277-283

[3] Atia MA, Ramirez FC, Gurudu SR. Quality monitoring in colonoscopy: Time to act. World J Gastrointest Endosc 2015; 7: 328-335

[4] Sint Nicolaas J, de Jonge V, de Man RA et al. The Global Rating Scale in clinical practice: a comprehensive quality assurance programme for endoscopy departments. Dig Liver Di 2012; 44: 919-924

[5] Arora G, Mannalithara A, Singh G et al. Risk of perforation from a colonoscopy in adults: a large population-based study. Gastrointest Endosc 2009; 69: 654-664

[6] Iqbal CW, Cullinane DC, Schiller H] et al. Surgical management and outcomes of 165 colonoscopic perforations from a single institution. Arch Surg 2008; 143: 701-707

[7] Korman LY, Overholt BF, Box T et al. Perforation during colonoscopy in endoscopic ambulatory surgical centers. Gastrointest Endosc 2003; 58: 554-557

[8] Rabeneck L, Paszat LF, Hilsden RJ et al. Bleeding and perforation after outpatient colonoscopy and their risk factors in usual clinical practice. Gastroenterology 2008; 135: 1899-1906.e1

[9] Kaminski MF, Regula J, Kraszewska E et al. Quality indicators for colonoscopy and the risk of interval cancer. N Engl J Med 2010; 362: 1795-1803

[10] Al-Rifaie A, El-Feki M, Al-Talib I et al. Does the withdrawal time affect adenoma detection in non-screening colonoscopies? Frontline Gastroenterol 2020; 11: 5-10
[11] Aranda-Hernández J, Hwang J, Kandel G. Seeing better-Evidence based recommendations on optimizing colonoscopy adenoma detection rate. World J Gastroenterol 2016; 22: 1767-1778

[12] Burr NE, Derbyshire E, Taylor J et al. Variation in post-colonoscopy colorectal cancer across colonoscopy providers in English National Health Service: population based cohort study. BMJ 2019; 367: 16090

[13] Thoufeeq MH, Rembacken BJ. Meticulous cecal image documentation at colonoscopy is associated with improved polyp detection. Endosc Int Open 2015; 3: E629-E633

[14] Wong MC, Ching JY, Chan VC et al. Determinants of bowel preparation quality and its association with adenoma detection: a prospective colonoscopy study. Medicine (Baltimore) 2016; 95: e2251

[15] Widjaja D, Bhandari M, Loveday-Laghi $V$ et al. Withdrawal time in excellent or very poor bowel preparation qualities. World J Gastrointest Endosc 2014; 6: 186-192

[16] Lee T], Blanks RG, Rees CJ et al. Longer mean colonoscopy withdrawal time is associated with increased adenoma detection: evidence from the Bowel Cancer Screening Programme in England. Endoscopy 2013; 45: 20-26

[17] Rees C], Thomas Gibson S, Rutter MD et al. UK key performance indicators and quality assurance standards for colonoscopy. Gut 2016; 65: 1923-1929

[18] Shenbagaraj L, Thomas-Gibson S, Stebbing J et al. Endoscopy in 2017: a national survey of practice in the UK. Frontline Gastroenterol 2019; 10: 7-15

[19] Murchie B, Tandon K, Zackria S et al. Can polyp detection rate be used prospectively as a marker of adenoma detection rate? Surg Endosc 2018; 32: 1141-1148

[20] Gavin DR, Valori RM, Anderson JT et al. The national colonoscopy audit: a nationwide assessment of the quality and safety of colonoscopy in the UK [published correction appears in Gut 2013; 62: 249. Gut 2013; 62: 242-249

[21] Rutter MD, Chattree A, Barbour JA et al. British Society of Gastroenterology/Association of Coloproctologists of Great Britain and Ireland guidelines for the management of large non-pedunculated colorectal polyps. Gut 2015; 64: 1847-1873

[22] Vavricka SR, Sulz MC, Degen L et al. Monitoring colonoscopy withdrawal time significantly improves the adenoma detection rate and the performance of endoscopists. Endoscopy 2016; 48: 256-262

[23] Ford JA, Jones AP, Wong $G$ et al. Weekend opening in primary care: analysis of the General Practice Patient Survey. Br J Gen Pract 2015; 65 : e792-e798

[24] Sanaka MR, Shah N, Mullen KD et al. Afternoon colonoscopies have higher failure rates than morning colonoscopies. Am J Gastroenterol 2006; 101: 2726-2730

[25] Subramanian S, Psarelli EE, Collins P et al. Colonoscopy performance is stable during the course of an extended three-session working day. Endosc Int Open 2015; 3: E494-E500

[26] British Society of Gastroenterology. BSG guidance on recommencing $\mathrm{Gl}$ endoscopy in the deceleration \& early recovery phases of the COVID-19 pandemic. 03 Mar 2021. https://www.bsg.org.uk/covid-19-advice/bsg-guidance-on-recommencing-gi-endoscopy-in-the-deceleration-early-recovery-phases-of-the-covid-19-pandemic/

[27] British Society of Gastroenterology. Endoscopy activity and COVID19: BSG and JAG guidance. 03 Mar 2021. https://www.bsg.org.uk/ covid-19-advice/endoscopy-activity-and-covid-19-bsg-and-jagguidance/

[28] Gulamhussein MA, Chaudhry S, Noor S et al. Safety in out-of-hours operating in trauma and orthopaedics at a district general hospital. Ann R Coll Surg Engl 2017; 99: 347-350

[29] Mothey MP, Schembri J, Thoufeeq M. PTU-054. Out of hours colonoscopy-are we compromising on quality? Gut 2017; 66: A77-A78 